\title{
Relevance of Kotter's Model for Change in Successfully Implementing Lean
}

\author{
Shovan Mishra \\ Department of Industrial and Systems Engineering, Auburn University \\ Auburn, Alabama- 36849, USA \\ shovan@auburn. edu
}

\begin{abstract}
Though lean consists of numerous tools and techniques that are applicable to entire value stream, there are not many guidelines on how to implement lean from the managerial perspective. Lean implementation has succeeded and failed in many different organizations. This paper attempts to map success factors of lean implementation as suggested by some studies with Kotter's eight steps model for change.
\end{abstract}

Keywords: Lean, managing change, lean implementation.

\section{Introduction}

Lean is the production philosophy which focuses on the elimination of waste (Muda) through continuous improvements of producing the product with no defects[1,2]. The concept of Muda originated in Japan and the philosophy was introduced by Taiichi Ohno from Toyota in early 1950s [3]. This concept was widely accepted later as Toyota Production System [1, 4] and was named as Lean by Womack et. al. [1]. From the operational perspective, lean involves implementation of all the tools and techniques at the shop floor which eliminates waste not only within the manufacturing plant but also in the entire supply chain [5-10]. Kaizen, setup time reduction, 5S, Kanban, JIT, cellular manufacturing, single piece flow, Single Minute Exchange of Dies (SMED), Supplier base reduction, Total Preventative Maintenance (TPM), are some of the examples of the tools and techniques used at the shop floor [9,11].

For an organization to be lean, it not only requires mastering the lean tools and techniques but it also requires a way of thinking that would focus on value adding processes, producing only the quantity demanded by the customers and establishing a culture to improve [7]. Shah and Ward define lean as "an integrated socio - technical system whose main objective is to eliminate waste by concurrently reducing or minimizing supplier, customer, and internal variability', [10].

There are no standard guidelines to each and every step of lean implementation [12- 14]. But for an organization to successfully implement lean from either mass production, job shop or any production system, it requires an expertise in change management in addition to the tools and techniques of Lean Manufacturing. Several researchers have emphasized that successful implementation of quality improvements 
requires wide-ranging change management programs that addresses both organizational and technological aspects of quality improvements [15 - 18]. Hence there is a rationale to explore the connection between lean manufacturing technique and change management principles. By nature, people want to stay in their comfort zones and they are resistant to change. Mismanaged change may result in higher cost, delay or even complete failure, while properly managed change can turn resistance into the source of innovation [19].

Change while implementing lean, may be arising from one or more of 1) differences in tools and techniques from Job Shop or Mass Production, 2) differences in Organizational Culture and 3) differences in National/ geographic culture. In spite of these differences and challenges in implementing change, there are numerous examples of successes and failures of lean implementation across cultures and nations. In this paper an attempt has been made to map the reasons for successes and failures of lean implementation as suggested in published journals with Kotter's 8 steps of Managing change $[20,21]$ and it is suggested that change management techniques are vital in successful implementation of lean. Though there are numerous change management techniques /models available, this study is limited to Kotter's model. A more extensive future study which takes into account of the reasons why lean implementation has succeeded or failed in a larger number of organizations and uses it to develop a customized change model for lean is suggested. This may help reduce the chances of lean implementation failure in the future.

\section{Methodology}

Chen and Meng, 2010 have extensively discussed why Chinese enterprises fail in deploying Lean [22] and Scherrer-Rathje et. al have discussed why lean implementation failed in the first attempt at Machine Inc and was successful in the second attempt at the same organization [23]. Major reasons discussed in both of these papers will be used to map with Kotter's Model for change [20, 21] and factors for success, of both, will be explained in terms of these models.

\section{Reasons for Lean Implementation Success and Failure}

\subsection{Reasons for Lean Implementation Success and Failure from Chen and Meng (2010)}

Chen and Meng studied more than 20 enterprises which implemented Lean Production for two years and were not successful. Their study revealed several reasons for failure and they also suggested how lean implementation could succeed in China (See Table 1). 
Table 1. Reasons for success and failure of lean as suggested by Chen and Meng, 2010

\begin{tabular}{|c|c|}
\hline $\begin{array}{l}\text { Reasons for Failure } \\
\text { - } \quad \text { Paid attention only to the tools } \\
\text { - } \quad \text { Expect very quick results } \\
\text { - Changing one tool while neg- } \\
\text { lecting others }\end{array}$ & $\begin{array}{l}\text { Reasons for Success } \\
\text { - } \quad \text { Get support from leaders and } \\
\text { involve management at different levels } \\
\text { - } \quad \text { Involve employees and help } \\
\text { change work habits } \\
\text { - } \quad \text { Emphasize standard work } \\
\text { - } \quad \text { Long term commitment } \\
\text { - } \quad \text { Establish HR system that sup- } \\
\text { ports lean philosophy } \\
\text { - Deploy Lean Systematically } \\
\text { and gradually }\end{array}$ \\
\hline
\end{tabular}

\subsection{Reasons for Lean Implementation Success and Failure from (Scherrer- Rathje, Boyle, \& Defrorin, 2009)}

Scherrer-Rathje et. al studied two lean implementation efforts within the same large, global company, Machine Inc. Lean implementation in Machine Inc. in 1997 was a failure while its implementation in 2006 was a success. Their study was based on 20 interviews that they conducted with managers and employees of Machine Inc which had experience/involvement in lean implementation in 2006 and/or 1997. See table 2 for reasons for successes and failures as indicated in their study.

Table 2. Reasons for success and failure of lean as suggested by Scherrer-Rathje et. al, 2009

\begin{tabular}{|c|c|}
\hline $\begin{array}{l}\text { Reasons for Failure } \\
\text { - No commitment from Senior } \\
\text { Management } \\
\text { - } \quad \text { No autonomy } \\
\text { - } \quad \text { No } \\
\text { Communication }\end{array}$ & $\begin{array}{l}\text { Reasons for Success } \\
\text { - Visible } \\
\text { Commitment } \\
\text { - } \quad \text { Formal mechanism for } \\
\text { autonomy } \\
\text { - Formal communication and } \\
\text { open discussion of short term and long } \\
\text { term goals } \\
\text { - Formal mechanism for long } \\
\text { term sustainability } \\
\text { - Communication of wins } \\
\text { Evaluation of Efforts }\end{array}$ \\
\hline
\end{tabular}

\section{$4 \quad$ Kotter's Eight Steps Model for Change}

Kotter's eight step model for change [21] comes from the eight common errors that managers make when they need to implement change [20]. These 8 steps are listed and briefly described in table 3 . 
Table 3. Kotter's Eight Step Model for Change by Kotter, 1995

"'Step 1: Establishing a sense of urgency"

- Top management support change when they understand why

- They are more likely to be involved and committed when there is urgency

“'Step 2: Forming a Powerful Guiding Coalition'”

- Group acting as a team is more likely to bring about change than a single person

- They facilitate better communication, knowledge sharing, stronger support and decision making

\section{“Step 3: Creating a Vision",}

- Creating a common vision helps channelize the change efforts

- A common strategy has to be developed on how to achieve the vision

\section{"Step 4: Communicating the vision",}

- This will help gain the necessary resources and also commitment from the workforce. It also helps to create the motivation and assistance to the members

\section{"Step 5: Empowering Others to act on the Vision",}

- Empowering employees to act on the vision will help maintain the credibility of change

\section{"Step 6: Planning for and Creating Short-Term wins"'}

- This will help boost motivation, morale and commitment of people at all levels

- This will also prevent people giving up when they are close to the achievement

\section{“Step 7: Consolidating Improvements and Producing Still More Change”,}

- Further improvements will be created by short term wins

“Step 8: Institutionalizing New Approaches"

- The change that has already been brought should be practiced and enforced everyday

\section{Mapping Chen and Meng, 2010's Reasons for Success with Kotter's Eight Step Model for Change}

According to Chen and Meng, it is very important for an organization to get support from leaders and involve management at different levels which corresponds with Kotter's step that says sense of urgency has to be established and there has to be guiding coalition. It is the sense of urgency that makes top management serious about 
the necessity of change, and make them committed to bring about this change. It may be in terms of providing resources, forming a team or prioritizing it in all of the communications.

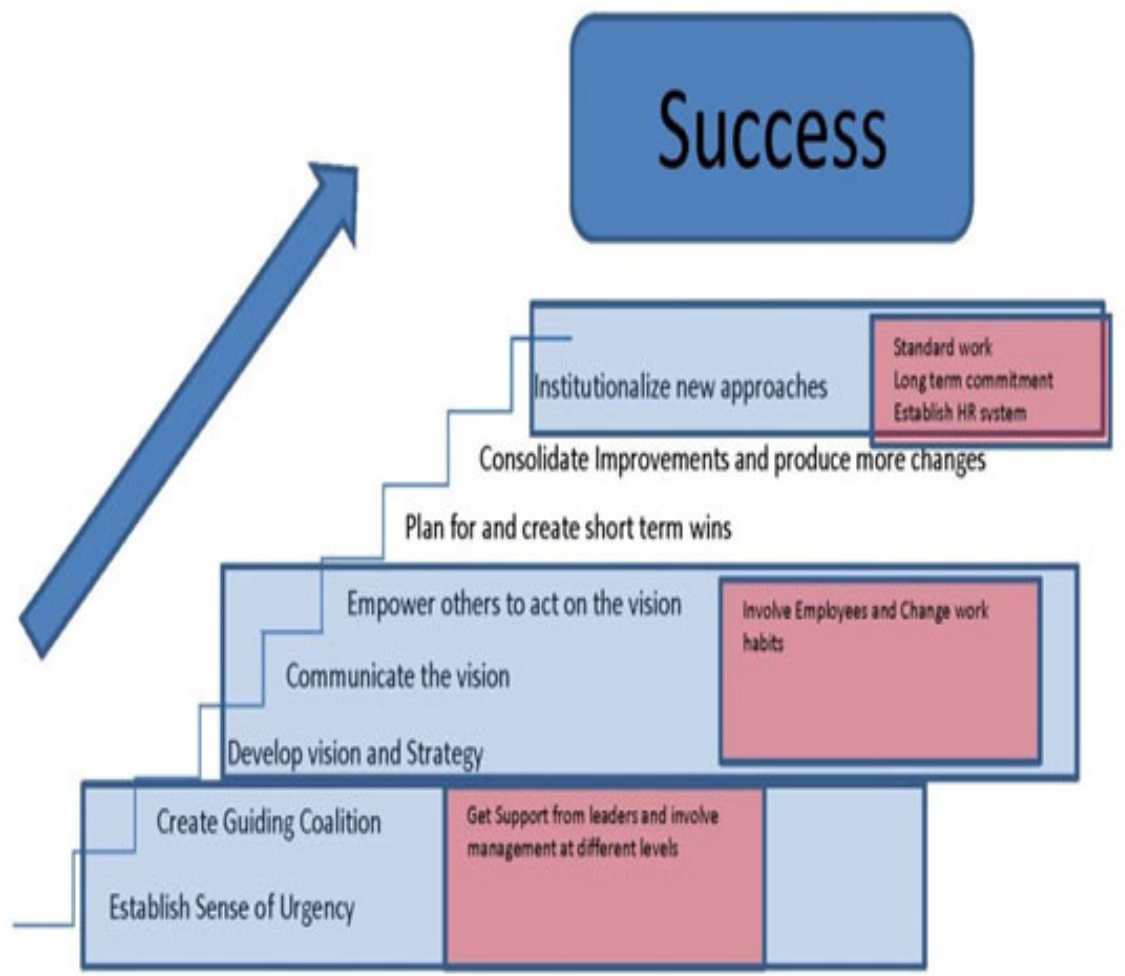

Fig. 1. Chen and Meng's reason for Success(in red) mapped with Kotter's model for change

Chen and Meng's saying that employment involvement and changing work habits could be matched with Kotter's 3rd, 4th and 5th steps.

Chen and Meng in their work also emphasized the need for standard work, long term commitments and establishing HR system which is actually 8th step of Kotter's Model. According to Kotter, change would never sustain and last till the change becomes the way of life. The right HR practices that motivate an employee who follow the standard work and penalize or take corrective action with those who do not will help institutionalize the change. And in the long run, the change may sustain.

\section{$6 \quad$ Mapping Scherrer-Rathje et. al. (2009)'s Reasons for Success with Kotter's Eight Step Model for Change}

According to Scherrer-Rathje et. al for lean to be implemented successfully, there has to be visible management support. Kotter's model says management commitment 
becomes visible when the sense of urgency is established and there is a critical mass of people who strongly believes in the necessity to bring about this change. They form a guiding coalition to work as a team and support every way possible to make it happen. Scherrer-Rathje emphasizes the need for open discussion of short term and long term goals which can be matched with Kotter's 3rd step. A vision and clear strategy help communicate the desired picture and also the ways to achieve it. Similarly Scherrer-Rathje et. al's formal Communication, formal mechanism for autonomy, communicate wins, evaluate changes and long term sustainability could be mapped with Kotter's Step 4, step 5, Step 6, Step 7 and Step 8.

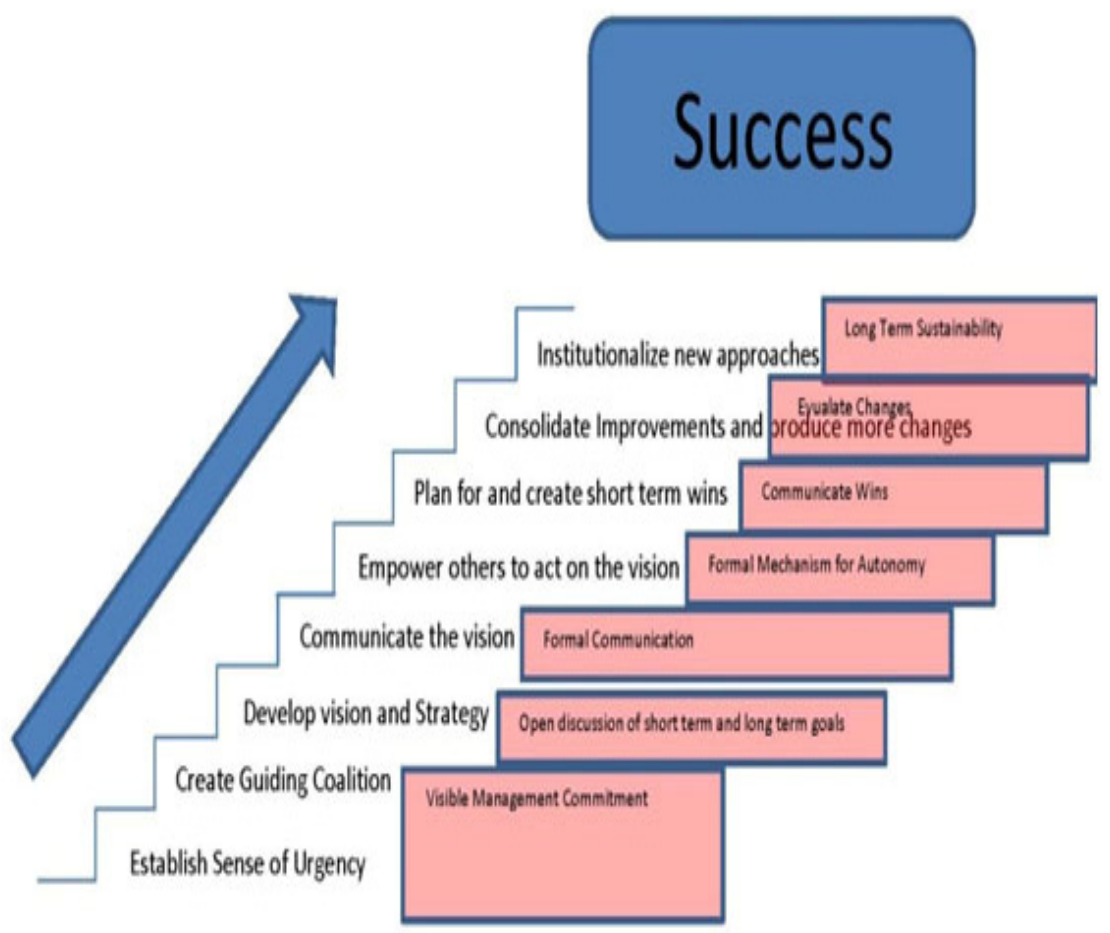

Fig. 2. Scherrer-Rathje et. al's reasons for success(in red) mapped with Kotter's Eight Steps Model

\section{$7 \quad$ Need to Modify Kotter's Eight Steps Model for Change to Implement and Sustain Lean}

Changing from any production system to Toyota Production System could be one big change which would affect entire value stream and everyone working in an organization. Following Kotter's eight steps for change could help successful implementation of lean. But as lean involves continuous improvement, it is expected for an organization to have to deal with changes continuously. So it is more important for lean organization to be change ready and have an established culture to change. 
The need for change in any lean organization may come from customer (internal or external), competitive position, potential gain or loss, threats or potential threats or technological changes. Hence there has to be continuous evaluation of the organization, departments, and business units. Creating urgency all the time in order to reduce waste and improve continuously may be challenging, but this could be driven by continuous evaluation and need assessment based on organizational performance with respect to the global competition. Hence incorporation of continuous evaluation of performance, continuous improvement, and need assessment is recommended.

\section{Conclusion}

Based on the factors for successful lean implementation and comparing it with Kotter's model for change; following eight steps model to implement lean could help successful implementation. Implementing lean based on the sole focus on lean tools could be very challenging. Several studies in the past have shown that lean can fail even with the sufficient knowledge about lean tools [22, 23]. In addition to the tools, successful lean implementation requires change management tools and techniques. It might be more practical for lean engineers to be trained in managing change. This study uses only one change management model and two cases of lean implementation successes or failures among many that have been published. More extensive study, which would include larger number of cases of lean implementation experience and also larger number of applicable change management models, is suggested. The study then could further be used to develop lean implementation model and guidelines to prevent failures of lean implementation.

\section{References}

1. Womack, J.P., Jones, D.T., Roos, D.: The Machine that Changed the World. Maxwell Macmillian International, New York (1990)

2. Womack, J., Jones, D.T.: Lean Thinking - Banish Waste and Create Wealth in your Corporation. Simon and Schuster, London (1996)

3. Dahlgaard-Park, S.: From ancient philosophies to TQM and modern management therories. Thesis No. FiF-a31. Linko Ping University, Sweden (2000)

4. Udagawa, M., Satoo, H., Nakamura, K., Nonaka, I.: Nihon Kigyoono Hinshitu Kanri (Quality Management in the Japanese Enterprises). Yuhikaku, Tokyo (1995)

5. de Treville, S., Antonakis, J.: Could lean production job design be intrinsically motivating? Contextual, configurational and levels of analysis issues. Journal of Operations Management, 99-123 (2006)

6. Hopp, W.J., Spearman, M.: To pull or not to pull: What is the question? Manufacturing and Service Operations Management, 133-148 (2004)

7. Liker, J.: The Toyota Way: 14 Management Principles from the World's Greatest Manufacturer. McGraw-Hill, New York (2004)

8. Narasimhan, R., Swink, M., Kim, S.: Disentanglingleaness and agility: An empirical investigation. Journal of Operations Management, 440-457 (2006) 
9. Shah, R., Ward, P.: Lean Thinking: Context, Practice bundles, and Performance. Journal of Operations Management, 129-149 (2003)

10. Shan, R., Ward, P.: Defining and Developing measures of lean production. Journal of Operations Management, 785-805 (2007)

11. White, R., Prybutok, V.: The relationship between JIT Practices and type of production System. Omega, 113-124 (2001)

12. Allen, J.: Making Lean Manufacturing work for you. Journal of Manufacturing Engineering, 1-6 (2000)

13. Nanni, A., Gregory, M., Platt, K.: Performance Measurement System Design. International Journal of Operations and Production Management, 80-116 (1995)

14. Oliver, N.: Lean Production Practices. British Journal of Management, 1-10 (1996)

15. Lathin, D.: Lean Manufacturing. American Society for Quality Journal, 2-9 (2001)

16. Lathin, D., Mitchell, R.: Lean Manufacturing: Techniques, People and Culture. Quality Congress Proceedings, 2-6 (2001)

17. Lathin, D., Mitchell, R.: Learning from Mistakes. Quality Progress, 1-8 (2001)

18. Hall, A.: Principles and Practices of Lean Manufacturing. University of Kentucky, Lexington (1995)

19. Waddell, D., Sohal, A.: Resistance: A constructive tool for change management. Management Decision, 543-548 (1998)

20. Kotter, J.: Leading Change. Harvard Business School Press, Cambridge (1996)

21. Kotter, J.: Leading Change: Why transformantion efforts fail. Harvard Business Review, 59-67 (1995)

22. Chen, L., Meng, B.: Why Most Chinese Enterprises Fail in Deploying Lean Implementation. Asian Social Science, 52-57 (2010)

23. Scherrer-Rathje, M., Boyle, T.A., Defrorin, P.: Lean, Take Two! Reflections from the second attempt at lean implementation. Business Horizons, 79-88 (2009) 